\title{
Factors Affecting Aesthetic Treatment Choices in Posterior Teeth
}

\author{
Mary A. Baechle ${ }^{1 *}$, Charles Janus ${ }^{2}$ and Al M. Best ${ }^{3}$
}

${ }^{1}$ Department of General Practice Dentistry, Virginia Commonwealth University School of Dentistry, USA

${ }^{2}$ Department of Prosthodontics, Virginia Commonwealth University School of Dentistry, USA

${ }^{3}$ Department of Periodontics, Virginia Commonwealth University School of Dentistry, USA

\begin{abstract}
Objectives: New developments of aesthetic restorative materials necessitate dentists choosing between aesthetic or unaesthetic restorations for posterior teeth. This study investigates correlations between dentists' choices of aesthetic or unaesthetic restorations and tooth type, as well as demographic information. The null hypothesis is that no relationship exists between treatment choices and demographic information.

Materials and methods: An online survey was deployed querying participating dentists for treatment recommendations for 15 clinical cases involving posterior restorations with intraoral occlusal views and bitewing images, from a menu of treatment options. Biographical and demographic data were collected about the dentists' practices. Subjects were volunteer subscribers to an online dental magazine with an estimated subscription of over three thousand. Being a cross sectional descriptive study, there are no controls or tests for examiner reliability. Analysis was accomplished using repeated-measures logistic regression.

Results: Respondents ( $\mathrm{N}=300), 16.9 \%$ female, $14 \%$ foreign. Tooth type (molar or premolar), was significant in the aesthetic restoration decision $(p<0.0001)$. Graduation decade when collapsed to graduates prior to 1980 and all others was significant $(p=0.0404)$. Type of practice was significant when collapsed into "educators", "military", "retired" and all other types $(p=0.0103)$. Adjusted odds of a premolar versus a molar being indicated for an aesthetic restoration is 3.67 (95\% Cl 3.07-4.38), and for other dentists versus educators, military and retired dentists indicating aesthetic restorations is $3.35(95 \% \mathrm{Cl} 2.06-5.42)$.

Conclusion: Despite continued improvements in aesthetic restorative materials, aesthetic restorations are still chosen for premolars significantly more than molars. Gender, nationality, decade of graduation and practice type were not significant. Practice type collapsed into educators, military and retired dentists was significant, as was graduation decade when collapsed into years prior to 1980 and all others.
\end{abstract}

Keywords: Aesthetics; Dental practice; Posterior restorations; Restorative dentistry; survey; Treatment-planning

\section{Introduction}

In today's society where such a strong emphasis is placed on physical appearance, a pleasant and attractive smile is no doubt of high importance. Furthermore, there is an increasing demand among dental patients for metal-free and tooth-colored aesthetic restorations [1-4]. Combined with improvements in aesthetic materials' properties such as the wear resistance and strength of composites [5,6], improved mechanical and physical properties of all-ceramic restorations [7] and reduced wear on opposing teeth by ceramics utilized for porcelain fused to metal restorations [8], aesthetic restorations offer a variety of viable alternatives to metal restorations when used in clinically appropriate settings $[6,2]$. Because of the continual development of aesthetic restorative materials, dentists and their patients have more options to choose from when restoring posterior teeth than in the past. These choices may be determined by a number of factors such as the patient's desires, the extent of new disease and existing oral conditions [9]. Demographic factors such as the dentist's location, year of graduation and gender may also influence restorative choices [10]. The purpose of this study is to survey dentists' choices of aesthetic versus unaesthetic replacement restorations for posterior teeth, to determine if there are any correlations regarding when aesthetic versus unaesthetic restorations are chosen, and to investigate the relationship between the dentist's treatment choice and the dentist's demographic information. The null hypothesis is that there is no relationship between dentists' treatment choices and their demographic information.

\section{Materials and Methods}

This study was approved for human subjects by a university
Institutional review board. An online survey of patients' posterior teeth requiring replacement of defective restorations was created, using a variety of examples of restorations of various sizes. Patients were chosen who presented with typical restorations and current bitewing radiographs. A Canon 20D digital camera with $100 \mathrm{~mm}$ macro lens and MR-14EX TTL Macro Ring Flash (Canon U.S.A, Inc, One Canon Plaza, Lake Success, NY 11042) was used to create occlusal view digital images of each patient's restoration and of each restoration's bitewing radiograph.

Using Inquisite Survey Builder (Version 6.5, Inquisite Inc. (formerly), Allegiance Software Inc., 805 Las Cimas Parkway, Suite 245, Austin, TX 78746), an online survey was produced including fifteen individual patient cases with the patient's age, gender, and intraoral and radiographic images of the tooth indicated for retreatment (Table 1). Respondents received the following instructions: "In each of the following fifteen cases, a tooth and the problem is described in the accompanying text. After reading the description and viewing the photograph and bitewing radiograph, choose from the drop-

*Corresponding author: Mary A. Baechle, Department of General Practice Dentistry, Virginia Commonwealth University School of Dentistry, USA, Tel: (804) 828-2977; Fax: (804) 828-3159; E-mail: mbaechle@vcu.edu

Received February 11, 2012; Accepted March 26, 2012; Published March 28 2012

Citation: Baechle MA, Janus C, Best AM (2012) Factors Affecting Aesthetic Treatment Choices in Posterior Teeth. Dentistry S10:001. doi:10.4172/2161-1122. S10-001

Copyright: () 2012 Baechle MA, et al. This is an open-access article distributed under the terms of the Creative Commons Attribution License, which permits unrestricted use, distribution, and reproduction in any medium, provided the original author and source are credited. 


\begin{tabular}{|c|c|c|c|}
\hline Tooth & Case & $\begin{array}{c}\text { Aesthetic } \\
\text { Choice }\end{array}$ & Image \\
\hline \multicolumn{4}{|c|}{ Premolars } \\
\hline $\begin{array}{l}\text { Maxillary Left } \\
\text { Second } \\
\text { Premolar }\end{array}$ & 12 & $74.4 \%$ & \\
\hline $\begin{array}{c}\text { Maxillary Right } \\
\text { First } \\
\text { Premolar }\end{array}$ & 9 & $77.8 \%$ & \\
\hline $\begin{array}{l}\text { Maxillary Right } \\
\text { First }\end{array}$ & 14 & $88.6 \%$ & \\
\hline $\begin{array}{l}\text { Maxillary Left } \\
\text { First }\end{array}$ & 1 & $88.7 \%$ & \\
\hline $\begin{array}{l}\text { Maxillary Right } \\
\text { Second } \\
\text { Premolar }\end{array}$ & 15 & $97.5 \%$ & \\
\hline $\begin{array}{l}\text { Maxillary Right } \\
\text { First } \\
\text { Premor }\end{array}$ & 3 & $98.2 \%$ & \\
\hline \multicolumn{4}{|c|}{ Molars } \\
\hline $\begin{array}{l}\text { Mandibular } \\
\text { Right Second } \\
\text { Molar }\end{array}$ & 11 & $43.8 \%$ & \\
\hline $\begin{array}{l}\text { Mandibular } \\
\text { Right Second }\end{array}$ & 5 & $52.0 \%$ & \\
\hline $\begin{array}{l}\text { Maxillary Left } \\
\text { Second }\end{array}$ & 7 & $53.7 \%$ & \\
\hline $\begin{array}{l}\text { Mandibular } \\
\text { Left Second }\end{array}$ & 2 & $54.8 \%$ & \\
\hline $\begin{array}{l}\text { Mandibular } \\
\text { Right First }\end{array}$ & 10 & $67.0 \%$ & \\
\hline $\begin{array}{l}\text { Maxillary Left } \\
\text { First } \\
\text { Molar }\end{array}$ & 13 & $70.9 \%$ & \\
\hline
\end{tabular}

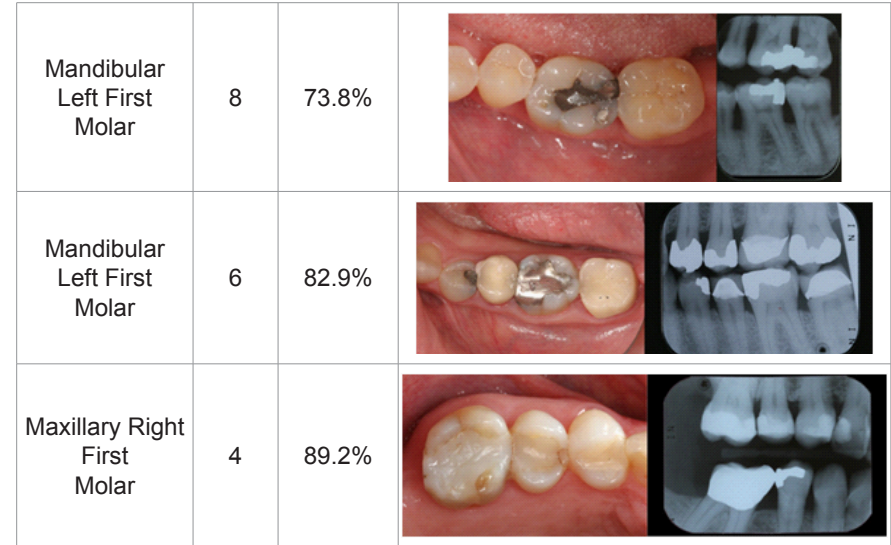

Table 1: Cases used for online survey with tooth type (premolar or molar), case number, and percentage of respondents choosing an aesthetic restoration with $95 \%$ confidence intervals. Reprinted with permission by the Academy of General Dentistry. (C) Copyright 2011 by the Academy of General Dentistry.

down menu the treatment you would recommend assuming a patient who has optimum health, no clinical symptoms, ideal occlusion, no parafunctional habits, good home care and sufficient resources to afford any treatment you propose. Although this will include the complete removal of the existing restoration, you expect very little extension of the cavity preparation [11]."

Respondents were then asked to choose the treatment from the following list of treatment options:

1. Only replace the restoration with amalgam

2. Only replace the restoration with composite resin

3. Only replace the restoration with metal inlay or onlay

4. Only replace the restoration with non-metal (resin or ceramic) inlay or onlay

5. Replace restoration and place all metal crown

6. Replace restoration and place porcelain fused to metal crown

7. Replace restoration and place aluminous or zirconium oxide crown (i.e.: Procera, Zirconia, Lava)

8. Replace restoration and place Lucite reinforced crown (i.e.: Empress, Ivoclar, Press Ceramic)

9. Other treatment (type in below)

The response items $2,4,6,7,8$ were considered by the authors as aesthetic restorative choices, which would be any tooth-colored restoration including composite resin, ceramic and porcelain fused to metal crowns; the others, except for 9, were considered unaesthetic. "Other treatment" was rarely chosen and was not used in the analyses.

The survey included questions regarding the dentist's year of graduation from dental school, formal post-doctorate training, gender, specific practice type and zip code of practice.

Representatives of Dentaltown.com, Inc. ${ }^{\circledR}$ (Towniecentral.com, L.L.C., a division of Farran Media, L.L.C. 10850 S. 48th Street Phoenix, AZ 85044) posted the survey and invited subscribers to participate.

Data analysis was accomplished using SAS software (SAS 9.2, and JMP 8.0.2, SAS Institute Inc., SAS Campus Drive, Building T, Cary, $\mathrm{NC}, 27513)$. The predictor variables relating to restoration choice were tested using repeated-measures logistic regression (PROC GENMOD 
with an exchangeable correlation GEE structure) to account for lack of independence across each set of responses.

\section{Results}

A total of 300 dentists responded to the survey. Thirteen countries outside of the United States accounted for forty-one (14\%) of the respondents. Eleven respondents were from Canada, 2 to 4 from Australia, Brazil, Ireland, New Zealand, and the United Kingdom, and one respondent each from Argentina, Bahamas, Israel, Malaysia, Norway, Peru, and Serbia. Fifty of 296 respondents (16.9\%) were female with a similar United States and international distribution. Most of the respondents $(n=285)$ reported providing fixed prosthodontic care (Table 2).

Decade of graduation ranged from before 1970 to 2008 , with 241 (81.2\%) respondents graduating after 1980. Most respondents (171/297 $=57.6 \%$ ) were private practitioners in solo practice or in group practices $(103 / 297=34.7 \%)$, and the remaining reported working in dental education, hospital-based practice, military setting, dental company, other or retired. Most respondents $(278 / 298=93.3 \%)$ reported General Dentistry as their primary practice discipline. Others $(13 / 298=4.4 \%)$ reported Prosthodontics, while the remainder reported Periodontics, Endodontics, Oral Surgery, Pediatric Dentistry or Other.

Figure 1 illustrates that for both direct and indirect restorations, an aesthetic restoration was more commonly chosen over an unaesthetic restoration. Figure 2 illustrates the distribution of aesthetic restorations by tooth type, molar and premolar. Preliminary analysis using repeatedmeasures logistic regression revealed a significant relationship between whether a respondent indicated an aesthetic restoration and tooth type $(\mathrm{p}<0.0001)$, with premolars indicated to be treated with an aesthetic restoration significantly more frequently than molars $(\mathrm{p}<0.0001)$. Although female dentists indicated aesthetic restorations slightly more frequently then male dentists, gender was not significant $(p=0.3045)$. Nationality of respondents was also found to be not significant. That is,

\begin{tabular}{|c|c|c|c|c|}
\hline Variable & Description & $\mathrm{N}$ & $\%$ & Total \\
\hline \multirow{2}{*}{ Gender } & Female & 50 & 16.9 & \multirow{2}{*}{296} \\
\hline & Male & 246 & 83.1 & \\
\hline \multirow{5}{*}{ Graduation Decade } & $<1970$ & 6 & 2.0 & \multirow{5}{*}{297} \\
\hline & $1970-1979$ & 50 & 16.8 & \\
\hline & $1980-1989$ & 81 & 27.3 & \\
\hline & $1990-1999$ & 79 & 26.6 & \\
\hline & $>1999$ & 81 & 27.3 & \\
\hline \multirow{2}{*}{ Nationality } & US & 252 & 86.0 & \multirow{2}{*}{293} \\
\hline & Outside US & 41 & 14.0 & \\
\hline \multirow{8}{*}{ Practice Types } & Solo Private Practice & 171 & 57.6 & \multirow{8}{*}{297} \\
\hline & Group Private Practice & 103 & 34.7 & \\
\hline & Dental Educator & 5 & 1.7 & \\
\hline & Military Dentist & 3 & 1.0 & \\
\hline & Hospital-based Practice & 3 & 1.0 & \\
\hline & Dental Company & 3 & 1.0 & \\
\hline & Retired Dentist & 1 & 0.3 & \\
\hline & Other & 8 & 2.7 & \\
\hline \multirow{7}{*}{ Practice Discipline } & General Dentistry & 278 & 93.3 & \multirow{7}{*}{298} \\
\hline & Prosthodontics & 13 & 4.4 & \\
\hline & Periodontics & 3 & 1.0 & \\
\hline & Endodontics & 1 & 0.3 & \\
\hline & Oral Surgery & 1 & 0.3 & \\
\hline & Pediatric Dentistry & 1 & 0.3 & \\
\hline & Other & 1 & 0.3 & \\
\hline
\end{tabular}

Table 2: Respondent's biographic and demographic data.
\% Distribution of Aesthetic Restorations by Direct or Indirect Type

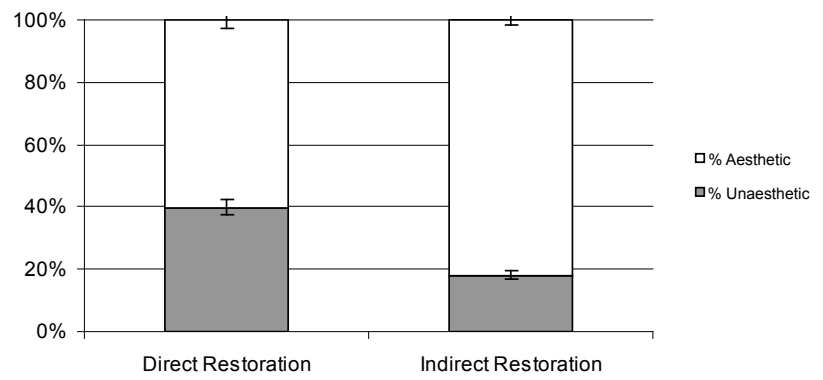

Figure 1: Percentage distribution of aesthetic and unaesthetic restorative choices by indirect or direct type with $95 \%$ confidence intervals.

$\%$ Distribution of

Aesthetic Restorations by Teeth

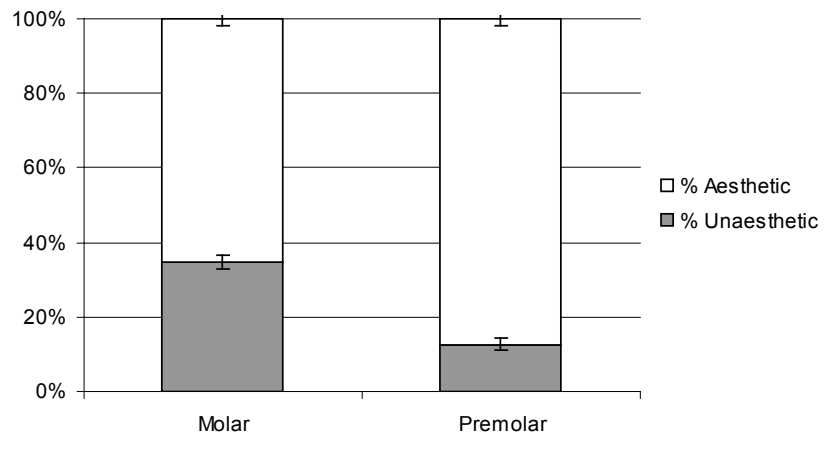

Figure 2: Percentage distribution of aesthetic and unaesthetic restorative choices by tooth type with $95 \%$ confidence intervals.

dentists practicing in the United States indicated aesthetic restorations no more often than dentists practicing outside the United States $(\mathrm{p}=$ $0.7612)$.

The respondent's decade of graduation was found to be not significant in the decision to place an aesthetic restoration $(\mathrm{p}=0.1320)$ Nor was it significant when adjusted for tooth type $(\mathrm{p}=0.3904)$. However, as illustrated in Figure 3, when the decade of graduation was collapsed to dentists graduating before 1980 and all other dentists, this was found to be significant, suggesting recent dentists were slightly more likely to indicate aesthetic restorations $(\mathrm{p}=0.0404)$. Although, when adjusted for tooth type, the collapsed decades of graduation was only marginally significant $(\mathrm{p}=0.0540)$.

Dentists' choices to indicate aesthetic restorations by type of practice (Figure 4) was found to not be significant $(p=0.4104)$. However, as illustrated in Figure 5, dental educators, military dentists and retired dentists collapsed into one group indicated unaesthetic restorations noticeably more frequently than a second group composed of all other dentists, with a significance $(\mathrm{p}=0.0103)$. The distribution of aesthetic restorations indicated by these collapsed groups was also found to be significant when adjusted for tooth type $(\mathrm{p}=0.0075)$.

The final model with independent variables of tooth type and collapsed practice types is illustrated in Table 3. From this model, the adjusted odds ratio of premolars indicated for aesthetic restorations versus molars is 3.67 (95\% CI 3.07-4.38). This model also illustrates dentists in the "all other dentists" group indicating an aesthetic 
restoration versus the group of dental educators, military dentists, and retired dentists at an adjusted odds ratio of 3.35 (95\% CI 2.06-5.42). This means that dentists outside the group of dental educators, military dentists, and retired dentists are over three times more likely to indicate an aesthetic restoration.

\section{Discussion}

The results of this study indicate a significant relationship between tooth type and choice of restoration, reveal that aesthetic restorations are more commonly chosen for both direct and indirect restorations, and reject the null hypothesis by revealing relationships between dentists' treatment choices and their demographic information in the areas of decade of graduation and practice type when collapsed into groups.

First of all, this study clearly indicates a significant relationship between tooth type and choice of restoration: aesthetic restorations are

\begin{tabular}{|c|c|c|c|}
\hline Source & df & Chi-Square & p value \\
\hline Tooth & 1 & 227.0865 & $<.0001$ \\
\hline Collapsed Practice Types & 1 & 40.0335 & $<.0001$ \\
\hline
\end{tabular}

Table 3: Adjusted odds ratio of tooth type and collapsed practice types and indications for aesthetic restorations.

\%Distribution of Aesthetic Restorations by Collapsed Respondent Graduation Decade

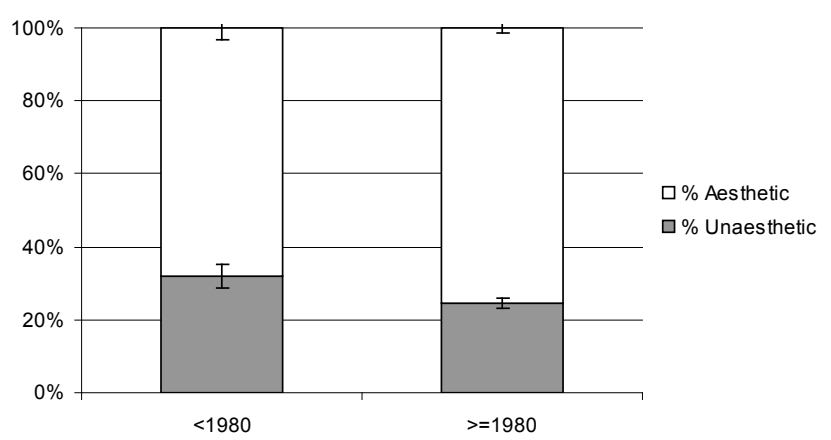

Figure 3: Percentage distribution of aesthetic and unaesthetic restorative choices by collapsed respondent graduation decade with $95 \%$ confidence intervals.

\section{$\%$ Distribution of Aesthetic Restorations} by Respondent Practice Type

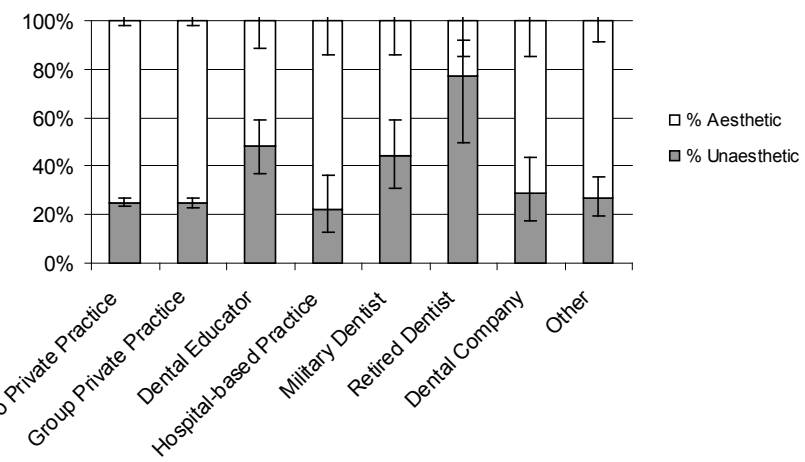

Figure 4: Percentage distribution of aesthetic and unaesthetic restorative choices by respondent practice types with $95 \%$ confidence intervals.

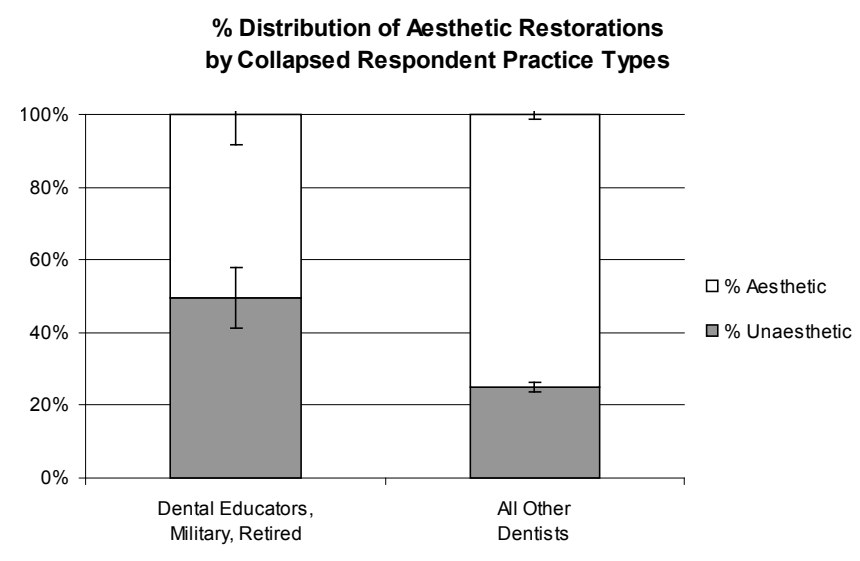

Figure 5: Percentage distribution of aesthetic and unaesthetic restorative choices by collapsed respondent practice types with $95 \%$ confidence intervals.

indicated on premolars significantly more often than molars, which reinforces current knowledge. Additionally, the results illustrated in Figure 1 show that regardless of what type of restoration was chosen, whether direct or indirect, an aesthetic restoration was more commonly chosen over an unaesthetic restoration. A similar result was found in another study that examined general dentists' use of materials for direct and indirect posterior intracoronal restorations that utilized practice philosophy, i.e. amalgam/mercury-free practice versus amalgam-use practice, as a factor in comparing any differences in restoration choice [12]. The study revealed that when either direct or indirect posterior restorations were chosen, dentists in both the amalgam-free and amalgam-use groups most commonly used an aesthetic material (composite resin for direct and ceramic for indirect restorations), and that direct composite restorations were placed more often than indirect aesthetic or unaesthetic restorations. Interestingly, the amalgam-free practice dentists, who would probably have more aesthetic-oriented practices, reported fewer complications with direct and indirect composite restorations than those dentists in amalgamuse practices. The authors of this study propose one reason for this, in light of possible bias could be due to the increased frequency of resinbased composite placement by dentists in the amalgam-free group, and their subsequent improved technique.

An increased amount of training in technique and familiarity with newer aesthetic restorations' properties may account for why dental graduates of 1980 and later in our study are slightly more likely to choose an aesthetic restoration. Although the respondent's year of graduation was not significant in the decision to place an aesthetic restoration in this study, an increased amount of training in technique and familiarity with newer aesthetic restorations' properties may affect future graduates' likeliness to choose an aesthetic restoration. Currently, most dental schools are teaching aesthetic restorative procedures, with many schools including formal aesthetic courses in their curriculum [13]. Additionally, most dental schools are now teaching improved methods of placing composite restorations [14]. Other aesthetic restorative procedures, such as all-ceramic restorations [13] and CAD/ CAM technology, are also present in some dental schools' curriculum. Additional reasons aesthetic restorations might be chosen in general may include an increase in patient demand for aesthetic and naturallooking restorations, as well as health and environmental concerns over the safety of mercury in amalgams over the last thirty years, with regulatory controls in some countries that limit or eliminate amalgam use [14]. The nationality of respondents, however, was found to not 
be significant, with dentists practicing in the United States indicating aesthetic restorations no more often than dentists practicing outside the United States.

Another group of respondent dentists who were more likely to indicate an aesthetic restoration included the collapsed group of dentists in solo and group private practice, hospital-based practice, dental companies and others. The type of practice seems to influence other clinical decisions as well, as reported in a study on the evaluation and treatment of existing restorations by dentists [15]. In this study, those dentists in solo or small group private practices were more likely to choose replacement of the entire restoration than their colleagues in large group practices or public health settings, who were more likely to choose prevention alone or prevention combined with other treatments, or no treatment options, respectively. With respect to dentists in large group or public health practices, Gordan et al. [15] states that while they "may have production or revenue incentives, this is not their main source of income. Therefore, participants in these types of practices may feel less pressured to recommend services that have higher fees." Similarly, dentists in our survey who are dental educators, military dentists or retired may not have a patient population who can afford aesthetic restorations, some of which may be higher in cost than unaesthetic restorations [16]. Because of the higher anticipated cost to the patient, these dentists may be less likely to recommend these types of restorations. Additionally, those who work in the public sector may think that unaesthetic restorations have a better longevity than aesthetic restorations, and thus may choose to place them more often than those in the private sector. A corresponding finding was reported in a study evaluating Finnish dentists' perceptions of direct dental restoration longevity [17]. In this study, it was found that those dentists in the private sector estimated the longevity of posterior composites, an aesthetic restoration, to be significantly longer than those in the public sector.

Of particular importance in this study were the survey participants' comments and what they revealed. Three common themes appeared throughout. First, some participant dentists wanted to choose more than one restorative option so as to be able to present the patient with more than one choice. One dentist wanted the option to offer no treatment and stated, "In several of these cases the tooth in question appeared to not need treatment". A second theme that emerged was basing one's treatment decisions on procedures and materials with which one is most familiar and comfortable. One participant commented, "I tend to be more old school and do treatments that I know will hold up", and another commented that the treatment choices "may come down to what works best in your hands". Likewise, another survey respondent noted, "Made me realize how limited my treatment planning options usually are - need to consider further training to expand my horizons". Although the survey instructions stated patients would have sufficient funds for any proposed treatment, by far the most common theme that emerged was being able to take patient financial concerns and desires into account when making the treatment choice. One survey respondent summarized this well when stating, "Difficult questions to answer because there was no discussion of patient concerns or desires noted, which plays a large role in treatment-planning." Based on this response and others similar to it, it appears dentists place a high importance on the cost of dental work to the patient, as well as the patient's desires and expectations, and take this into serious account when treatment planning. A recent study by Weiner et al. revealed that the ability to afford cosmetic dentistry caused some level of anxiety in over half the survey respondents [18]. This emphasizes, moreover, that patient financial concerns should not be underestimated when presenting restorative options.

\section{Conclusion}

The results of this study reveal tooth type, molar and premolar, to be a significant factor in the decision to indicate an aesthetic restoration, with aesthetic restorations indicated on premolars significantly more often than molars. Furthermore, the null hypothesis of this study was rejected in that dentists' practice type, when collapsed into two groups of dental educators, military dentists and retired dentists versus all other respondents, was found to be significant in the decision to indicate an aesthetic restoration, as well as graduation decade, when collapsed into dentists graduating 1980 and later versus earlier graduates. Dentists' gender and nationality were not significant, as well as decade of graduation and practice type, when not collapsed into groups. Responses from participants in this study suggest that further research in this area may help raise awareness among dental educators, practicing dentists and dental companies as to what type of restorations their colleagues are choosing. Future studies that take into account other factors that may influence dentists' restorative choices may also be of value.

\section{References}

1. Christensen GJ (2009) Porcelain-fused-to-metal versus zirconia-based ceramic restorations, 2009. J Am Dent Assoc 140: 1036-1039.

2. Magne $P$ (2006) Composite resins and bonded porcelain: The postamalgam era? J Calif Dent Assoc 34: 135-147.

3. Raigrodski AJ, Harrison JD (2003) Esthetic techniques and restorative systems used in the second-year undergraduate dental curriculum. J Esthet Restor Dent 15: 233-243.

4. Holand W, Schweiger M, Watzke R, Peschke A, Kappert H (2008) Ceramics as biomaterials for dental restoration. Expert Rev Med Devices 5: 729-745.

5. Suzuki S (2004) Does the wear resistance of packable composite equal that of dental amalgam? J Esthet Restor Dent 16: 355-365.

6. Puckett AD, Fitchie JG, Kirk PC, Gamblin J (2007) Direct composite restorative materials. Dent Clin North Am 51: 659-675.

7. Conrad HJ, Seong WJ, Pesun IJ (2007) Current ceramic materials and systems with clinical recommendations: a systematic review. J Prosthet Dent 98: 389404.

8. Christensen GJ (2007) Choosing an all-ceramic restorative material: Porcelainfused-to-metal or zirconia-based? J Am Dent Assoc 138: 662-665.

9. Clarkson JE, Worthington HV, Davies RM (2000) Restorative treatment provided over five years for adults regularly attending general dental practice. J Dent 28: 233-239.

10. Rosenstiel SF, Land MF, Rashid RG (2004) Dentists' molar restoration choices and longevity: A web-based survey. J Prosthet Dent 91: 363-367.

11. Janus C, Sbeih I, Best AM (2011) The role of volume of multi-surface restorations in posterior teeth: Treatment options. Gen Dent 59: 486-491.

12. Haj-Ali R, Walker MP, Williams K (2005) Survey of general dentists regarding posterior restorations, selection criteria, and associated clinical problems. Gen Dent 53: 369-375.

13. Osborne PB, Skelton J (2002) Survey of undergraduate esthetic courses in U.S. and Canadian dental schools. J Dent Educ 66: 421-425.

14. Kovarik RE (2009) Restoration of posterior teeth in clinical practice: evidence base for choosing amalgam versus composite. Dent Clin North Am 53: 71-76. 
Citation: Baechle MA, Janus C, Best AM (2012) Factors Affecting Aesthetic Treatment Choices in Posterior Teeth. Dentistry S10:001. doi:10.4172/21611122.S10-001

15. Gordan VV, Garvan CW, Richman JS, Fellows JL, Rindal DB, et al. (2009) How dentists diagnose and treat defective restorations: evidence from the dental practice-based research network. Oper Dent 34: 664-673.

16. American Dental Association (2009) Survey of Dental Fees website Accessed 19 August 2010. http://www.ada.org/1442.aspx
17. Palotie U, Vehkalahti MM (2009) Finnish dentists' perceptions of the longevity of direct dental restorations. Acta Odontol Scand 67: 44-49.

18. Weiner AA, Stark PC, Lasalvia J, Navidomskis M, Kugel G (2010) Fears and concerns of individuals contemplating esthetic restorative dentistry. Compend Contin Educ Dent 31: 446-448.
This article was originally published in a special issue, Infection Prevention \& Control in Dental Practice handled by Editor(s). Dr. Andrew Smith, University of Glasgow, UK 